\title{
Implications on Comparing Power Planning Characteristics in Foreign Countries and China
}

\author{
Fuwei Zhang ${ }^{\mathrm{a}}$, Wenjing Wang ${ }^{\mathrm{b}}$ \\ School of North China Electric Power University, Beijing 102206, China. \\ azfw@ncepu.edu.cn, b807694235@qq.com
}

\begin{abstract}
The characteristics, methods and experiences of electric power planning in some power enterprises in United States, Japan and Western Europe were analyzed and summarized. Suggestions were made for current electric power planning of our country and for the planning works of our power industry before 2020 .
\end{abstract}

Keywords: Electric power planning; green power; integrated resource planning; electric power marketization.

\section{Status of China's Electric Power System Planning}

With the rapid development of power industry, there is tremendous growth in capacity and transmission lines. Since 1987, power generation capacity was more than 100GW, 200GW in 1995, $300 \mathrm{GW}$ in 2000 , and $760 \mathrm{GW}-800 \mathrm{GW}$ in 2020 . Until 1995 , China's annual power generation capacity has been ranked second in the world. Unit capacity of Generator has developed to $800 \mathrm{MW}-1000 \mathrm{MW}$ from 300MW- 600MW, China's power industry has entered a period of large units, during the high voltage, however, some traditional conventional planning methods cannot meet the current situation, so the development of the system put forward many new requirements to the power planning, design, operation and manufacturing.

There are many problems in China's power system planning:

(1) Planning is of a relatively narrow viewing angle

Electricity is an industry in strong association with economic and social development. At present, China's power industry planning was not able to fully integrated environmental protection, human resources management, land resources, financing, and so on. Waste gas, waste water and ash generated by the plant operation is very serious to the environmental. In addition, the construction and operation of power requires a lot of funds, equipment and primary energy supply, human resources, and the need for the coordinated development of society as a whole. Thus, China's electric power planning should take full account of the use of diverse resources, reduce supply and price risks, and promote the economic development of specific regions, safeguard national security, reduce coal mine casualties, save water and reduce water pollution control costs.

(2) Power grid construction is lagging behind

Since planning is not detailed and in place, the new line appeared in overload and put into operation less than a year. I Even worse, long-term load rate of some transmission line was less than 10 percent after construction. In some places, due to the lag of transmission lines, power plants construction have not construction power, and the progress speed of project is slow, which increases the construction cost and the difficulty of construction. There is "four no hydropower" project in some places, which leading that the construction quality cannot be guaranteed and some major security risks were buried.

In addition, the power transmission capacity is weak, electricity in west and north is difficult to be delivered to the middle and eastern region that is load-intensive, which exacerbates coal supply and transport tensions, reducing the efficiency of energy distribution. Meanwhile, the transmission capacity of interconnected power grid is insufficient, and the superiority of large power grids was not played well. The existing power grid cannot meet the needs of long-distance, high-capacity transmission. 
(3) Lack of global interest

In order to attract investment and safeguard local interests, government planned to reduce the power plant capacity. Development efforts on Hydropower is not enough, especially in the well-adjusted performance small-scale hydropower, and nuclear power, high-energy power generation and new energy power generation ratio is too small; Moreover, power peak-valley difference is too large and peaking capacity is insufficient, which weakening the power balance ability of the power grid itself, and exacerbating the contradictions dry peak in place grid.

Our existing power sector planning process does not completely identified demand-side energy efficiency programs as alternatives to increase supply. Although some demand-side programs has access to investment and implemented, the importance attached them is insufficient

\section{Practice of Foreign Power Planning}

There is no centralized power generation planning In the countries whose Electricity Market Management has been loosened, such as United States, Britain and Australia. Increasing the generation capacity is dependent on the economic signals and information of demand for electricity provided by market, but in general they have a uniform transmission planning [1-3].

\subsection{United States.}

Green electricity means power from wind, small hydro, solar, geothermal, biomass and other renewable energy. From the beginning of the 1970s, green electricity planning on renewable energy sources has become an alternative to conventional thermal power construction, and it occupies a certain position in the power industry in the United States. According to statistics, green electricity produced by renewable energy sources will reach 113.5 billion kW.h in the year of 2020, which accounting for 8.9 percent of all electrical energy, and small hydropower generating is 6.6 percent.

By the year of 2025, the proportion of Green electricity will reach 15 percent, and the power provided by renewable energy will be five times than all the electrical energy in 2020. In the US states, according to their own degree of power market competition, they designed a green power pricing and selection of projects to encourage consumers to use green power. The United States is doing inspection of the power industry, including tariff effect (RIM), the participants, the total resource cost (TRC) and social inspection. Based on these tests, consider impact on economic and social planning of implementing Power Demand Side Management (DSM). Since the 1980s, the National Electricity Company Management Board set up an energy-efficient Committee to implement the minimum cost plan.

\subsection{Japan.}

In Japan, electricity is dependent on fossil fuels and nuclear energy. Electricity price ranks second in the OECD, higher 20 percent than the average price. The government is trying to reduce electricity prices, which could lead to power industry restructuring, in which peak shifting and load management activities are considered the foundation. Part of the revenue of power companies was used to improve energy efficiency, advisory services and equipment rental. However, the purpose of these activities is only to improve the load characteristics and their public identities.

There are many planning measures in Japan. Firstly, greatly reduce investment in infrastructure, and improve the input and output efficiency. Secondly, improve efficiency, saving vigorously wages and other expenses with relying on scientific and technological progress. Thirdly, to improve equipment operating rate, shorten the maintenance shutdown of the nuclear power plant. Although Japan also regarded liberalizing electricity planning as a goal, they adhere to the precautionary principle and carry out liberal reforms on the premise of ensuring a stable investment, reliable supply of electricity. It is suitable for Japan that resources are import-dependent.

\subsection{Western Europe.}

(1) The United power system and networking planning are implemented in Western Europe

In Western Europe, the united power system includes the power system of France, Germany, Italy, Belgium, Switzerland, Spain and other countries. By the year of 1996, the installed capacity of the 
joint grid is $430 \mathrm{GW}$. Recently several countries of the Baltic Rim and Russia networking are also taken into account. In the Security guidelines formulated by Coordination Committee Transmission (UCPTE), there are some main content concerning the transmission section. To handle bus fault, the most important switching station should run with double bus bars. In the reliability guidelines adopted by of Western Europe power system, Italian criterion is the most distinctive. Italy adopted cost effective - benefits in Grid Planning, which made system reliability assessment. by calculating the risk index,

(2) Implement alternative electricity energy planning

The proportion of nuclear power in France has accounted for 78.2 percent, it is not lack of electricity, but is the world's largest net exporter of electricity, whose profit is about 2.6 billion euros per year. Therefore, France's main goal is to make full use of existing equipment, including nuclear power plants and fuel cycle, develop the next generation of reactors to improve the utilization of natural uranium, and minimize waste. In Germany, coal-fired electricity generation was replaced by natural gas and renewable energy, and this trend is expected to continue. Meanwhile, the German government is committed to stopping the use of nuclear power, thus nuclear energy is expected to be phased out in Germany.

\section{Suggestion}

By comparing the power planning characteristics of domestic and foreign, the following suggestions are proposed.

(1) Power planning is coordinated with energy, environment and economic development on the basis of meeting the needs, to achieve comprehensive, coordinated and sustainable development. First, the power of alternative energy sources should also be considered for use, in order to strengthen the awareness of energy conservation. Secondly, take the green power planning routes, increase research and development investment, and occupied the commanding heights of green power technologies. Thirdly, to enhance consumer awareness of green electricity, promote the development of green power from the demand side.

(2) When formulating electricity planning, adhere to a clear direction, our own reality, overall planning and step by step. More importantly, we should always upload the basic value orientation to break the monopoly, encourage competition, improve efficiency, reduce the price and serve the community. In addition, while the implementing each step, stick to principles of planning from the overall, step by step, simulated operation, gradual and smooth transition.

(3) Integrated resource planning (IRP) and rolling plan should be adopted as soon as into power planning, make coal, oil, transportation planning in the same period, and propose the macro-control measures to implement planning. Thus, emphasis on planning should converted from simply protecting the supply-side capacity to steering to combining both strengthen supply capacity and the demand side management, so that make contribution to resource - conserving society.

(4) We must insist on combining competition and government regulation to establish the electricity market in the power planning. Moreover, the Development pattern of the power industry should be converted into full play the role of market mechanism guided by government from strong regulated planed by government.

\section{Conclusion}

Power planning under market conditions is of great difference with traditional electricity planning. The power industry market-oriented abroad start early than that of domestic, so we should make full use of foreign experience, combined with China's national conditions, to explore the power planning method is suitable for China. 


\section{References}

[1] WALID E K, KANKAR B, YASSERH, et al. Optimal investment for distributed generation in a competitive electricity market [J]. IEEE Transaction on Power Systems, 2004, 19(3):1674-1684.

[2] Fucheng Cao, Zhiheng Wei. Guidelines of transmission planning in the united states and implications for China [J]. China Power, 2006, 12(39):76-78

[3] DSAA A. Integrated resource planning (IRP) and power sector reform in developing countries [J]. Energy Policy.2005 (33):1271-1285. 